\title{
Extended network analysis: from psychopathology to chronic illness
}

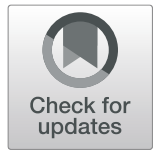

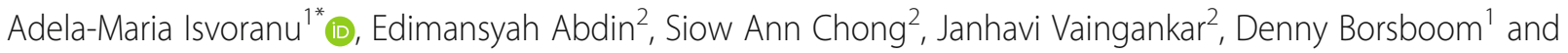
Mythily Subramaniam²

\begin{abstract}
Background: Understanding complex associations between psychopathology and chronic illness is instrumental in facilitating both research and treatment progress. The current study is the first and only network-based study to provide such an encompassing view of unique associations between a multitude of mental and physical healthrelated domains.
\end{abstract}

Methods: The current analyses were based on the Singapore Mental Health Study, a cross-sectional study of adult Singapore residents. The study sample consisted of 6616 respondents, of which $49.8 \%$ were male and $50.2 \%$ female. A network structure was constructed to examine associations between psychopathology, alcohol use, gambling, major chronic conditions, and functioning.

Results: The network structure identified what we have labeled a Cartesian graph: a network visibly split into a psychopathological domain and a physical health domain. The borders between these domains were fuzzy and bridged by various cross-domain associations, with functioning items playing an important role in bridging chronic conditions to psychopathology.

Conclusions: Current results deliver a comprehensive overview of the complex relation between psychopathology, functioning, and chronic illness, highlighting potential pathways to comorbidity.

Keywords: Mental health, Physical health, Chronic illness, Psychopathology, Network psychometrics, Network analysis, Functioning

\section{Background}

Mental illness is one of the most pressing contemporary problems, with impact on health, social and economic issues. Despite significant research efforts, common mental disorders within the general population remain a major concern, with reports as high as $28.8 \%$ for anxiety disorders, $20.8 \%$ for mood disorders, and $14.6 \%$ for substance use disorders [1], as well as rates of up to $40 \%$ for subjects with a mental disorder to meet criteria for another class of lifetime disorder [2].

\footnotetext{
* Correspondence: isvoranu.adela@gmail.com

'Department of Psychology, Psychological Methods, University of Amsterdam, Nieuwe Achtergracht 129B, 1018 WT Amsterdam, The Netherlands

Full list of author information is available at the end of the article
}

In addition to high comorbidity between mental disorders, there is also vast evidence that people with common mental health conditions are at higher risk of developing physical illness, and conversely people with a diagnosis of physical illness are at higher risk of developing mental health conditions [3]. For instance, robust associations between immunological/ inflammatory conditions and mood disorders [4] have been identified, with depressed patients being $60 \%$ more likely to develop diabetes than their non-depressed counterparts and prevalence rates of diabetes as high as three times greater in subjects with bipolar disorder [3]. Further, in patients with schizophrenia, cardiovascular disease is the most common cause of death [5]. Of note, while highly

(c) The Author(s). 2021 Open Access This article is licensed under a Creative Commons Attribution 4.0 International License, which permits use, sharing, adaptation, distribution and reproduction in any medium or format, as long as you give appropriate credit to the original author(s) and the source, provide a link to the Creative Commons licence, and indicate if changes were made. The images or other third party material in this article are included in the article's Creative Commons licence, unless indicated otherwise in a credit line to the material. If material is not included in the article's Creative Commons licence and your intended use is not permitted by statutory regulation or exceeds the permitted use, you will need to obtain permission directly from the copyright holder. To view a copy of this licence, visit http://creativecommons.org/licenses/by/4.0/ The Creative Commons Public Domain Dedication waiver (http://creativecommons.org/publicdomain/zero/1.0/) applies to the data made available in this article, unless otherwise stated in a credit line to the data. 
relevant, the comorbidity between mental health and physical conditions is often neglected [6]. Here we argue better understanding this comorbidity may lead to improved prognosis and outcomes. The aim of the current study was therefore to delve into the relationship between mental and physical health conditions, as to highlight features important in explaining the development of this comorbidity.

In recent years it has been suggested that some symptoms of particular diagnoses, but not all, may account for the comorbidity patterns between diagnoses, indicating that symptoms may have a unique role and may not be interchangeable [7]. This line of reasoning, now known as the network framework [8] has been proposed as an innovative tool in the study of psychopathology, and in the past decade it has grown prominent in the fields of psychiatry and clinical psychology [9]. Within this framework, the focus shifts from the diagnostic level to the symptom level, with the aim to highlight the unique role of symptoms, and their potential causal associations. Network structures may therefore be useful tools to study both within-diagnoses and betweendiagnoses symptom associations.

Further, the network approach suggests that the boundaries between mental and physical disorders are porous [10], as physical symptoms can cause psychopathological symptoms (e.g., pain $->$ fatigue $->$ depressed mood) and vice versa (e.g., depressed mood -> alcohol use - > liver damage). If so, it is crucial to chart the pathways by which these influence each other, as to ultimately reach better treatment targets. The current research aims to highlight features that may account for comorbidity between diagnoses and provide an encompassing view of unique associations between psychopathological conditions and chronic illness and functioning. To this end, we aimed to constructed a large network structure, encompassing a multitude of symptoms and other health-related dimensions, ranging from general psychopathology, to psychosis, alcohol use, chronic physical conditions and functioning and healthrelated quality of life (HRQoL). To our knowledge, this is the first and only network-based study encompassing such as multitude of health-related domains, as well as the only existing network study concerned with the comorbidity between mental and physical health conditions.

\section{Methods}

\section{Sample}

The sample analyzed ( $n=6616$ respondents) was part of the Singapore Mental Health Study (SMHS), a crosssectional, population-based, epidemiological study of adult Singapore residents aged 18 years and above. The study aimed to establish lifetime and 12-month prevalence of mental disorders, as well as the current use of mental health services, treatment gaps and loss of role functioning. The subjects were randomly selected from a national registry that maintains the names, sociodemographic details (e.g., age, gender and ethnicity), and household addresses of all residents in Singapore. Inclusion criteria were being a Singapore citizen or resident, 18 years or older, and able to speak and understand English, Chinese or Malay. Exclusion criteria included being incapable of doing an interview due to severe physical or mental health conditions, language barriers, living outside the country, institutionalized or hospitalized throughout the duration of the survey period, as well as incomplete or incorrect addresses. A disproportionate stratified sampling was used where the 3 main ethnic groups (Chinese, Malays, and Indians) were sampled in equivalent proportion of about $30 \%$ each. Further details of the sample are available in the cited papers $[11,12]$.

\section{Measures}

All measures used in this study are reported in Table 1 and described in Appendix 1 in the Supplement. Due to the skip-structure of the interviews, we selected and included only items that were answered by the full sample, focusing on sub-clinical levels of psychopathology. Overall, we included items pertaining to the World Health Organization-Composite International Diagnostic Interview (WMH-CIDI) [13], a modified CIDI checklist of chronic medical conditions, the South Oaks Gambling Screen (SOGS) [14], and the EQ-5D [15].

\section{Statistical analysis}

\section{Network construction}

We constructed an undirected, weighted network model and included all measures described in Table 1 as nodes, with each edge in the network reflecting the pairwise conditional relation between two nodes, while controlling for all other nodes in the network. We fitted an Ising Model to the data using the eLasso technique implemented in the IsingFit $R$-package, version 0.3.1 [16]. The technique is based on the Ising Model as used in statistical physics, and uses $l_{1}$ regularized logistic regression [17], commonly referred to as the eLasso, conjointly with the extended Bayesian Information Criterion (EBIC) [18]. The method has been shown successful in identifying the most relevant features of a network constructed from binary data [16].

We visualized the network using the qgraph $R$-package version 1.6.4 [19]. Blue (red) edges represent positive (negative) associations, and the thicker the edge, the stronger the association between two nodes [20]. The layout of the network is based on the FruchtermanReingold algorithm [21], which places nodes with 
Table 1 Study measures

\begin{tabular}{|c|c|c|c|}
\hline Domain & Instrument & Measure & Items \\
\hline $\begin{array}{l}\text { General } \\
\text { Psychopathology }\end{array}$ & WMH-CIDI & Screening Section & $\begin{array}{l}26 \text { items measuring: smoking, mental and physical health, anxiety, intermittent } \\
\text { explosive disorder, depression, generalized anxiety attack, specific phobias, social } \\
\text { phobia, agoraphobia, attention deficit hyperactivity disorder, oppositional defiant } \\
\text { disorder, separation anxiety. }\end{array}$ \\
\hline Psychosis & WMH-CIDI & Psychosis Screen & 1 item measuring psychosis \\
\hline $\begin{array}{l}\text { Obsessive- } \\
\text { Compulsive } \\
\text { Disorder }\end{array}$ & WMH-CIDI & $\begin{array}{l}\text { Obsessive- } \\
\text { Compulsion Disorder } \\
\text { Section }\end{array}$ & 1 item measuring compulsions, 1 item measuring obsession \\
\hline Alcohol Use & WMH-CIDI & Alcohol Use & 1 item measuring age of first alcoholic beverage \\
\hline Gambling & SOGS & Lifetime Gambling & 1 item measuring lifetime gambling \\
\hline $\begin{array}{l}\text { Major Chronic } \\
\text { Conditions }\end{array}$ & $\begin{array}{l}\text { CIDI checklist of } \\
\text { chronic medical } \\
\text { conditions }\end{array}$ & $\begin{array}{l}\text { Major Chronic } \\
\text { Medical Conditions }\end{array}$ & $\begin{array}{l}6 \text { items measuring presence of asthma, high blood sugar / diabetes, } \\
\text { hypertension, back problems, migraine headaches, and other chronic conditions }\end{array}$ \\
\hline $\begin{array}{l}\text { Health-Related } \\
\text { Quality of Life }\end{array}$ & $E Q-5 D$ & $\begin{array}{l}\text { Quality of Life and } \\
\text { Functioning }\end{array}$ & $\begin{array}{l}5 \text { items measuring mobility, self-care, usual activities, pain or discomfort, and anx- } \\
\text { iety or depression. }\end{array}$ \\
\hline
\end{tabular}

Abbreviations: WMH-CIDI World Health Organization-Composite International Diagnostic Interview, SOGS South Oaks Gambling Screen

stronger and/or more connections closer to the center of the network and to each other.

\section{Centrality analysis}

To investigate the centrality of each node in the network, we computed strength [22] as a centrality measure. Node strength is a measure of the number and strength of connections, quantifying how well a node is directly connected to other nodes. Previous research showed strength to be the most robust centrality measure [23].

\section{Network stability}

To investigate the robustness and replicability of results we performed accuracy and stability checks using the $\mathrm{R}$ package bootnet version 1.2.4 [23]. We assessed the accuracy of the network connections, the stability of strength centrality, and tested whether the network connections and centrality estimates for different variables differ from each other.

\section{Results}

\section{Patient characteristics}

The study sample consisted of 6616 respondents, of which $49.8 \%$ were male and $50.2 \%$ female. The demographic profile distribution of subjects is reported in Table 2, and the item frequency and domain distribution are reported in sTable 1 in the Supplement. After treating "don't know" and "refused answers" as missing data, there were overall less than $0.5 \%$ missing data on the general psychopathology, psychosis, OCD, gambling, and chronic conditions variables. In addition, there were $1.13 \%$ missing data on the variable measuring age of first alcoholic drink, and $15.45 \%$ missing data on the EQ-5D, due to the instrument being administered at a later time point than the rest of the measures. Given that the estimation methodology employed requires full data, we imputed missing data ${ }^{1}$ using the mice $R$-package version 3.6.0. prior to fitting the model [24].

\section{Network analysis}

The resulting network structure is presented in Fig. 1. The physical and mental health self-report variables were not reverse-coded, a higher value thus indicating better health reports. For all other variables, a higher value indicates more problems. Overall, all nodes were associated with at least one other node in the network.

On a global level, the network was visually divided into two noticeable domains: a mental health domain consisting mainly of psychopathological nodes (to the right), and a physical health domain consisting mainly of nodes pertaining to physical problems, such as chronic conditions and functioning (to the left). We coin this

Table 2 Demographic profile distribution

\begin{tabular}{llll}
\hline Demographic & Value & Frequency & $\%$ \\
\hline Gender & Male & 3295 & $49,8 \%$ \\
Age group & Female & 3321 & $50,2 \%$ \\
& $18-34$ & 2292 & $34,6 \%$ \\
& $35-49$ & 2359 & $35,7 \%$ \\
Marital Status & $50-64$ & 1551 & $23,4 \%$ \\
& $65+$ & 414 & $6,3 \%$ \\
& Married & 4293 & $64,9 \%$ \\
& Separated & 31 & $0,5 \%$ \\
& Divorced & 230 & $3,5 \%$ \\
Language & Widowed & 236 & $3,5 \%$ \\
& Never Married & 1826 & $27,6 \%$ \\
& English & 5262 & $79,6 \%$ \\
& Chinese & 540 & $8,2 \%$ \\
& Malay & 814 & $12,3 \%$ \\
\hline
\end{tabular}




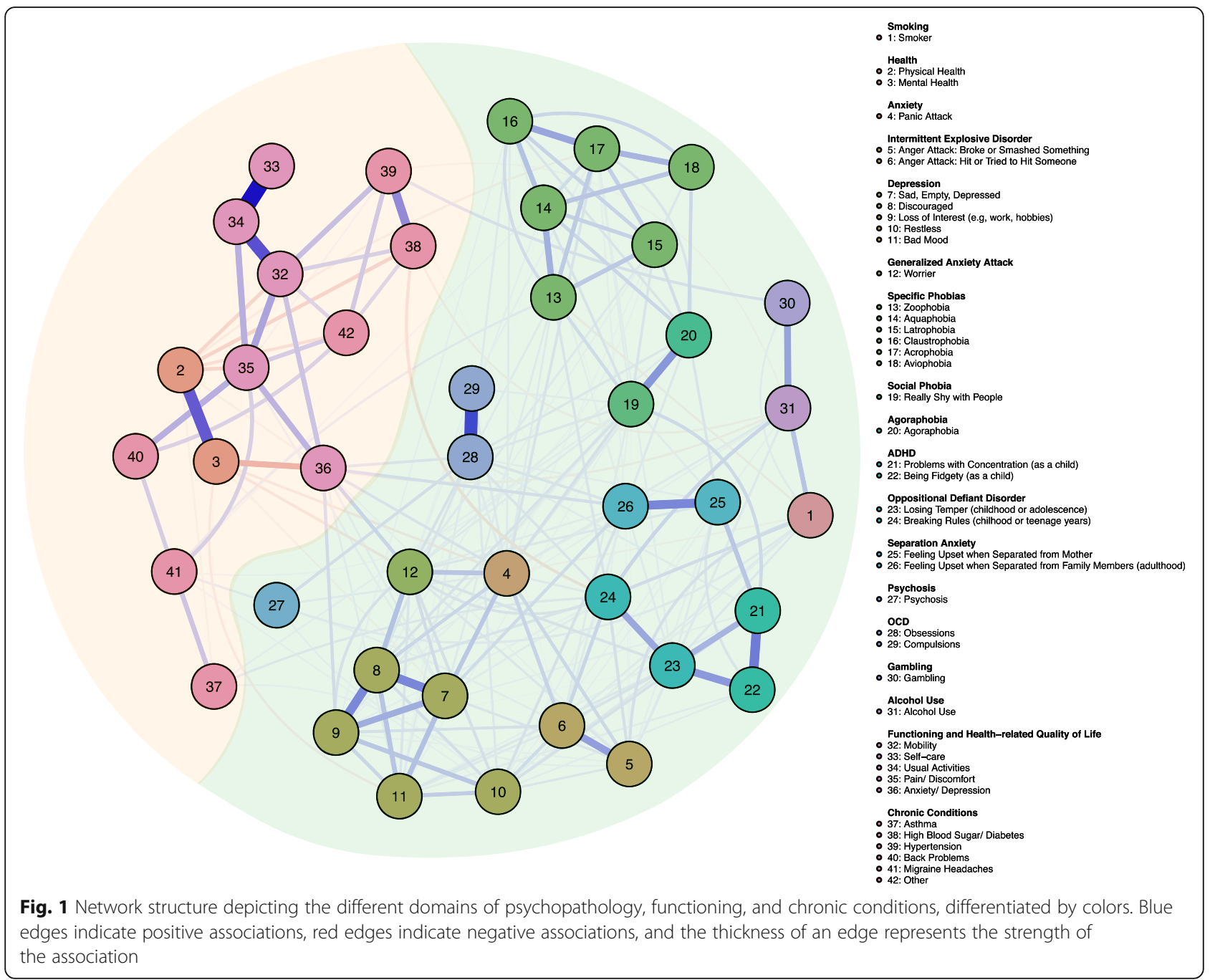

conspicuously separated structure a Cartesian graph, after the dualist philosopher Descartes. Noticeably, however, the borders between these two domains are fuzzy and bridged by various cross-domain associations.

To summarize the results of our analysis, we will first highlight within-domain associations, followed by between-domain associations. Of note, within each domain (i.e., psychopathological and physical), there are multiple clusters differentiated by color, pre-defined according to classic diagnostic categories (such as the Diagnostic and Statistical Manual of Mental Disorders [25]). We will address these as clusters, to differentiate them from what we refer to as domains (i.e., the Cartesian graph).

\footnotetext{
${ }^{1}$ We chose imputation over listwise deletion, as most missing data were on the EQ-5D variable and were missing at random, as a result of later administration of the test. Of note, listwise deletion would have resulted in a large loss of information of data available on the other 38 variables.
}

\section{Within-domain associations}

Within-domain associations were common and stronger than between-domain associations, with most items being associated with a multitude of other items within the same domain.

Especially, the psychopathological domain displayed high connectivity, almost all associations being positive (i.e., an increase in one item predicts an increase in another item). The items belonging to attention deficit hyperactivity disorder (ADHD), oppositional defiant disorder (ODD), and separation anxiety were strongly interrelated. Smoking, gambling, and alcohol use were all linked with each other. The anxiety items were associated with depression and intermittent explosive disorder. Worrier was connected with all depression items and panic attack, which was in turn associated with feeling sad, empty, depressed, and both anger attack items. Obsessions were associated with agoraphobia, being really shy with people, and with psychosis. 
The physical health domain, while less wellconnected, displayed strong connectivity within and between functioning items and chronic conditions. Notably, chronic conditions displayed a less clear clustering pattern and did not group as well together, but were divided by the functioning items. Mobility was associated with hypertension, high blood sugar/ diabetes, and other chronic conditions. Pain/ discomfort was associated with back problems and other chronic conditions. Self-report measures of physical and mental health clustered within the functioning cluster, with higher reports of physical health being negatively associated with mobility, high blood sugar/ diabetes, other chronic conditions and pain/ discomfort. Higher reports of mental health were negatively associated especially with anxiety/ depression.

\section{Between-domain associations}

While the two domains of the Cartesian graph are prominent and less connected, the borders between these are fuzzy and bridged by various cross-domain associations. The item measuring anxiety/ depression according to the functioning measure was the main item connecting the two domains, located in the center of the network. This was strongly associated especially to the psychopathology items panic attack, loss of interest, worrier, obsessions, feeling upset when separated from family members (adulthood) and to the physical health items mobility, pain /discomfort, and mental health reports.

Other between-domain associations include hypertension, visibly and strongly associated with gambling, asthma associated with the mood item restless, social phobia, and with the ODD item breaking rules during childhood or teenage years. The item migraine headaches was associated with psychosis, and very weakly with the mood item restless, as well as with some types of phobia. High blood sugar/ diabetes was mostly, albeit weakly, negatively associated with ODD and alcohol use.

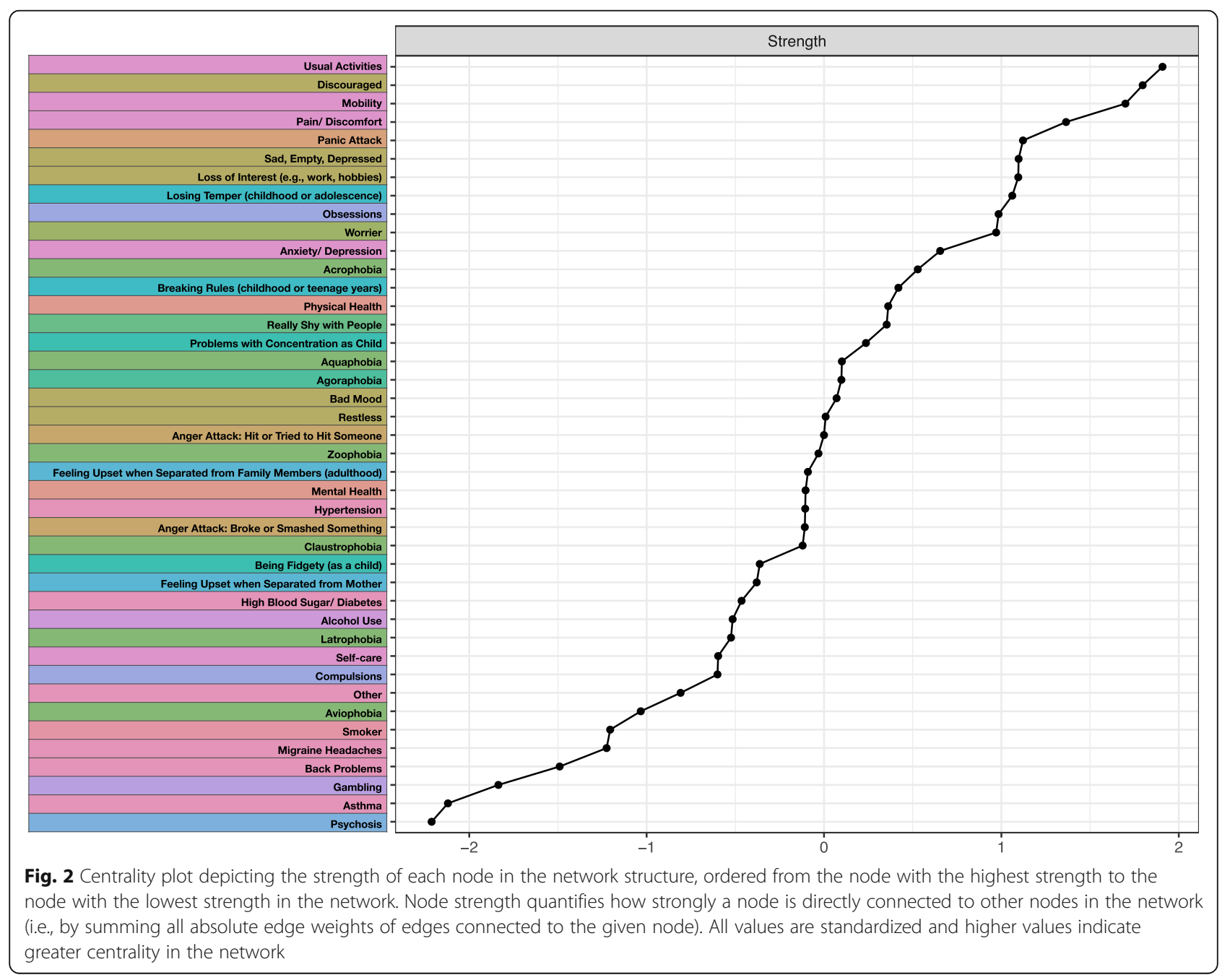




\section{Centrality analysis}

The centrality plot is presented in Fig. 2. The top 3 items with the highest strength centrality were usual activities, discouraged, and mobility, ${ }^{2}$ while the 3 least central items in terms of strength were psychosis, asthma, and gambling. ${ }^{3}$ sFigure 4 in the Supplement provides an overview of all the significant and non-significant differences between centrality items.

\section{Network Replicability and robustness}

Appendix 3 and sFigures 2, 3, 4, 5 in the Supplement detail on the results of the accuracy and stability checks. Overall, our results suggest that the network model is very stable, many of the identified edges and centrality measures are significantly different from each other, and all findings are interpretable.

\section{Discussion}

The current study used a network approach in an aim to uncover associations, at a subclinical level, between a wide array of psychopathological conditions, chronic illness and functioning. To our knowledge, this is the first study to focus on such a multitude of complex relations between different physical and health-related domains. Overall, we identified what we have labeled a Cartesian graph: a network graph split into two visible domains: a (mainly) psychopathological domain (more generally referred to as the mental health domain), and a (mainly) functioning and chronic conditions domain (more generally referred to as the physical health domain). The borders between these two domains are fuzzy and bridged by various cross-domain associations.

To date, there is wide evidence supporting the comorbidity between physical conditions and mental disorders $[3,4]$, with a majority of findings indicating mood and anxiety disorders as the main comorbid feature [26-29]. Although the current study identified few links between specific anxiety- and depression-related symptoms and chronic conditions, most chronic conditions were associated with items related to functioning, which were in turn associated to reports of anxiety/ depression-the main bridging item between the domains. Notably, the anxiety/ depression item, as well as the remaining functioning items were designed to measure the presence of current symptomatology, while the rest of psychopathological items were designed to measure lifetime presence

\footnotetext{
${ }^{2}$ Based on bootstrapping [23], these items were significantly different from many of the other items in the network, though not significantly different from each other and from other high centrality items, including depressed, loss of interest, and pain/ discomfort.

${ }^{3}$ Based on bootstrapping [23], these items were significantly less central from many of the other items in the network, but not significantly different from each other and from other low centrality items, including back problems and migraine headaches.
}

of symptomatology. Taken together and in line with high rates of relapse for depression [30] and generalized anxiety disorders [31, 32], these findings suggest that overall lifetime symptomatology may predict current symptomatology (i.e., subjects with lifetime symptoms may report more current symptoms and vice versa), and current symptomatology may in turn be linked to current levels of functioning. Further, our results indicate that functioning plays a unique role and is a crucial bridging component in linking chronic conditions to psychopathology. It may thus be that when chronic conditions are associated with a decrease in functioning and thus low HRQoL reports, psychopathological symptoms may be triggered. Similarly, chronic psychopathology affecting daily-life functioning may lead to a rise in other physical chronic conditions. Previous research indeed identified that better functional status and fewer depressive symptoms were significantly associated with a higher quality of life in adults with chronic conditions [33]. Centrality analyses further support these findings, with functioning and depression items being most central in the current network structure. In addition, in line with outcomes showing high comorbidity between physical conditions and mental conditions [3, 4], we found that self-reports of physical and mental well-being were strongly linked together, indicating that subjects reporting poorer mental health are more likely to also report poorer physical health and vice versa.

Other between-domain links included associations between asthma and depression, social phobia, and ODD. Previous research identified that children diagnosed with and taking medication for asthma were more likely to endorse common behavioral problems [34], while lifetime and current asthma diagnosis were associated with a range of mental disorders, including social phobia and affective disorders [35]. We further found hypertension and gambling to be linked, even when controlling for alcohol use and smoking, supporting findings on the detrimental effect of gambling on physical health [36]. Further, within the psychopathology domain, smoking, gambling, and alcohol were well-clustered items, the comorbidity between the addictions being welldocumented [37-39]. Smoking was further associated with psychosis, in line with evidence that smoking is common in psychotic disorders [40]. In addition, interestingly, the psychosis item was the only psychopathological item that fell in between the two domains of the network, being connected to psychopathology, but also to the chronic conditions through its association with migraine headaches. Side-effects of antipsychotic medication can include headaches [41, 42], but some evidence suggests severe forms of migraine-such as migraine aura-can also be associated with psychotic manifestation [43-45]. Psychosis and obsessions were 
also interrelated, indicating this association may already present at subclinical levels of psychopathology, and not only in patients [46], or in subjects at ultra-high risk for psychosis [47]. Finally, the obsessions item was one of the more central items in the network, being extensively associated to psychopathology. Of note, recent research showed OCD to have one of the largest treatment gaps $(89.8 \%)$ in Singapore [48], highlighting the importance of addressing symptomatology early and encouraging helpseeking behavior.

Finally, within-domain and within-cluster associations were stronger and predominantly positive, suggesting activation may spread faster within the same domain. In addition, some psychopathology symptom clusters displayed lower connectivity to others (e.g., specific phobias) than other symptom clusters (e.g., depression, anxiety, childhood disorders), indicating the latter may be more comorbid. These results align with previous research [7] investigating the network structure of the Diagnostic and Statistical Manual for Mental Disorders (DSM) [49]. Of note, previous research [7] relied on a skip structure, which is problematic when constructing network structures [50]. The current study overcame this limitation ${ }^{4}$ and is thus the first to approximately assess the structure of a wide variety of mental disorder symptoms, overcoming an important limitation of earlier work.

The current research aimed to take a first step towards identifying important features in the development of the comorbidity between mental and physical health, by zooming into and bringing together a multitude of health-related domains. While the research is exploratory in nature and preliminary, a key finding of our research is the crucial role played by functioning in bridging chronic conditions and psychopathology. This finding indicates that when chronic conditions are associated with a decrease in functioning, psychopathological symptoms may be triggered and vice-versa. Functioning may thus be a potential key target for treatment: by tackling problems in functioning early on we may be able to circumvent problems arising in other healthrelated domains. Further, functioning was especially related to current complaints of anxiety and depression, which were in turn related to long-term psychopathological complains, adding to the importance of addressing functioning complaints in intervention strategies. In addition, we identified gambling to be one of the addictions that paved ways to both physical and mental health problems and psychosis to be the main

${ }^{4}$ While the design of the current study originally relied on a skipstructure (to unburden data collection), here we focused on complete cases only and did not include severity of items in the analyses (i.e., focused on sub-clinical levels of psychopathology), thus overcoming this limitation. psychopathological domain to fall in between the physical and mental health domains. These results indicate that approaching these conditions holistically by taking into account both physical and mental health complaints is essential, as leaving out any one component may lead to a faster activation of problems in that specific domain, ultimately leading to feedback loops and complaints in both physical and mental health domains. Alongside these main findings, we discussed within-domain and within-cluster associations, pinpointing to depression, anxiety, and childhood disorders as being more connected clusters and thus more likely to lead to activation of other disorders and therefore comorbidity.

Of note, as highlighted above, our study is exploratory in nature and preliminary. Future research is essential for expanding on our findings, by including more diverse samples (e.g., focus on a world-wide population, clinical populations, and so forth), as well as a wider array of variables concerned with chronic conditions. Here, due to the nature of data collected, we were limited to investigating only five types of common chronic conditions, as well as five functioning problems. Network studies designed specifically to investigate this comorbidity could expand on the inclusion and selection of variables, as to provide further information on this comorbidity. Alongside the replication of our results, this will enable better pinpointing of treatment targets, which may provide to be essential in reducing the comorbidity between mental and physical health. Ultimately, experimental designs built upon results from exploratory research can further lead to insights into treatment development.

In sum, we highlighted complex associations between a multitude of health-related domains. Our main findings include the identification of (1) a Cartesian graph consisting of a mental and a physical health domain, (2) functioning playing a crucial role in bridging chronic conditions and psychopathology, and (3) several withinand between-domain associations informative for potential pathways to comorbidity.

\section{Limitations}

Our results should be considered in light of several limitations. First, the current study was based on crosssectional data which precluded strong inferences on causal direction, and therefore any conclusions regarding direction of causality are tentative. Second, the WMHCIDI [13] interview encompasses self-report statements, and may be prone to bias due to social desirability or under-reporting of symptomatology. Further, the current study focused on complete data cases and did not include severity of items in the analyses. Clinical samples may display different patterns of associations and current results were discussed in light of subclinical level of psychopathology. Finally, the study was carried out in 
a very specific population of residents of Singapore, and therefore the extent to which they generalize to other cultures is not yet known.

\section{Conclusions}

This study provides rich information on the complex associations between mental health and chronic conditions. Our results highlight the central role of functioning in bridging psychopathology to chronic conditions, as well as a multitude of potential within- and between-domain pathways to comorbidity, which can often be overlooked or simplified by reductionist approaches to psychopathology. We assert investigating such unique associations between different health domains may highlight potential pathways to comorbidity, ultimately aiding research and treatment targets.

\section{Supplementary Information}

The online version contains supplementary material available at https://doi. org/10.1186/s12888-021-03128-y.

Additional file $\mathbf{1}$ This Supplementary Materials file has been provided by the authors to give readers additional information about their work. It includes a further description of the measures used in the study, information about item frequency and domain distribution, as well as accuracy and stability checks of the network model.

\section{Abbreviations}

HRQoL: Health-related quality of life; SMHS: Singapore Mental Health Study; WMH-CIDI: World Health Organization-Composite International Diagnostic Interview; SOGS: South Oaks Gambling Screen; ADHD: Attention deficit hyperactivity disorder; ODD: Oppositional defiant disorder; DSM: Diagnostic and Statistical Manual for Mental Disorders

\section{Authors' contributions}

Al performed all analyses for the current manuscript. Al, in collaboration with $E A, M S$, and DB formulated the research question and wrote the manuscript. EA, SAC, JV, and MS contributed to the data collection. All authors approved the final manuscript

\section{Funding}

This research was supported by funding from the Singapore Millennium Foundation and the Ministry of Health, Singapore. Al was supported by the Netherlands Organization for Scientific Research (NWO) Grant no. 406.16.516. DB was supported by the European Research Council (ERC) Consolidator Grant no. 647209. The funding bodies did not have any role in the design of the study and collection, analysis, and interpretation of data and in writing the manuscript.

\section{Availability of data and materials}

Data availability: Due to the strict regulations and its sensitive nature, supporting data cannot be made openly available. The data is available on request from the senior author.

\section{Ethics approval and consent to participate}

The SMHS was reviewed and approved by the National Healthcare Group Domain-Specific Review Board. All participants provided written informed consent. Further information is available in the SMHS [11].

\section{Consent for publication}

Not applicable.

\section{Competing interests}

The authors declare that they have no competing interests.

\section{Author details}

'Department of Psychology, Psychological Methods, University of Amsterdam, Nieuwe Achtergracht 129B, 1018 WT Amsterdam, The Netherlands. ${ }^{2}$ Research Division, Institute of Mental Health, Singapore, Singapore.

Received: 15 June 2020 Accepted: 17 February 2021

Published online: 27 February 2021

\section{References}

1. Kessler RC, Zhao S. The prevalence of mental illness. In: Scheid TL, Brown $\mathrm{TN}$, editors. A handbook for the study of mental health: social contexts, theories, and systems. 2nd ed. New York: Cambridge University Press; 2010. p. $46-53$.

2. Merikangas KR, He JP, Burstein M, Swanson SA, Avenevoli S, Cui L, et al. Lifetime prevalence of mental disorders in U.S. adolescents: results from the national comorbidity survey replication-adolescent supplement (NCS-A). J Am Acad Child Adolesc Psychiatry. 2010;49:980-9.

3. Doherty AM, Gaughran F. The interface of physical and mental health. Soc Psychiatry Psychiatr Epidemiol. 2014;49:673-82.

4. Merikangas KR, Calkins ME, Burstein M, He JP, Chiavacci R, Lateef T, et al. Comorbidity of physical and mental disorders in the neurodevelopmental genomics cohort study. Pediatrics. 2015;135:e927-38.

5. Brown S. Excess mortality of schizophrenia. A meta-analysis. Br J Psychiatry. 1997;171:502-8.

6. Sartorius N. Comorbidity of mental and physical disorders: a key problem for medicine in the 21st century. Acta Psychiatr Scand. 2018;137:369-70.

7. Boschloo L, Van Borkulo CD, Rhemtulla M, Keyes KM, Borsboom D, Schoevers RA. The network structure of symptoms of the diagnostic and statistical manual of mental disorders. PLoS One. 2015;10:e0137621.

8. Borsboom D, Cramer AOJ. Network analysis: an integrative approach to the structure of psychopathology. Annu Rev Clin Psychol. 2013;9:91-121. https://doi.org/10.1146/annurev-clinpsy-050212-185608.

9. Robinaugh DJ, Hoekstra RHA, Toner ER, Borsboom D. The network approach to psychopathology: a review of the literature 2008-2018 and an agenda for future research. Psychol Med. 2020;50(3):353-66.

10. Borsboom D, Cramer AOJ, Kalis A. Brain disorders? Not really: why network structures block reductionism in psychopathology research. Behav Brain Sci. 2019;42:1-63.

11. Subramaniam M, Vaingankar J, Heng D, Kwok KW, Lim YW, Yap M, et al. The Singapore mental health study: an overview of the methodology. Int J Methods Psychiatr Res. 2012;21:149-57.

12. Chong SA, Abdin E, Vaingankar JA, Heng D, Sherbourne C, Yap M, et al. A population-based survey of mental disorders in Singapore. Ann Acad Med Singap. 2012;41:49.

13. Kessler RC, Üstün BB. The world mental health (WMH) survey initiative version of the World Health Organization (WHO) composite international diagnostic interview (CIDI). Int J Methods Psychiatr Res. 2004;13:93-121.

14. Lesieur HR, Blume SB. The south oaks gambling screen (SOGS): a new instrument for the identification of pathological gamblers. Am J Psychiatry. 1987;144:11841188.

15. Herdman M, Gudex C, Lloyd A, Janssen M, Kind P, Parkin D, et al. Development and preliminary testing of the new five-level version of EQ-5D (EQ-5D-5L). Qual Life Res. 2011;20:1727-36.

16. Van Borkulo CD, Borsboom D, Epskamp S, Blanken TF, Boschloo L, Schoevers RA, et al. A new method for constructing networks from binary data. Sci Rep. 2014;4:1-10.

17. Tibshirani R. Regression selection and shrinkage via the lasso. J R Stat Soc B. 1994;58:267-88. https://doi.org/10.2307/2346178.

18. Chen J, Chen Z. Extended Bayesian information criteria for model selection with large model spaces. Biometrika. 2008;95:759-71.

19. Epskamp S, Cramer AOJ, Waldorp LJ, Schmittmann VD, Borsboom D. qgraph : Network Visualizations of Relationships in Psychometric Data. J Stat Softw. 2012;48:1-18. https://doi.org/10.18637/jss.v048.i04.

20. Costantini G, Epskamp S, Borsboom D, Perugini M, Mõttus R, Waldorp LJ, et al. State of the aRt personality research: a tutorial on network analysis of personality data in R. J Res Pers. 2015;54:13-29.

21. Fruchterman TMJ, Reingold EM. Graph drawing by force-directed placement. Softw Pract Exp. 1991;21:1129-64. 
22. Opsahl T, Agneessens F, Skvoretz J. Node centrality in weighted networks: generalizing degree and shortest paths. Soc Networks. 2010;32:245-51. https://doi.org/10.1016/j.socnet.2010.03.006.

23. Epskamp S, Borsboom D, Fried El. Estimating psychological networks and their accuracy: a tutorial paper. Behav Res Methods. 2017;50:195-212.

24. Van Buuren S, Groothuis-Oudshoorn K. mice: Multivariate imputation by chained equations in R. J Stat Softw. 2011;45:1-67. https://doi.org/10.1177/ 0962280206074463.

25. American Psychiatric Association. DSM-IV. 2000.

26. Scott KM, Bruffaerts R, Tsang A, Ormel J, Alonso J, Angermeyer MC, et al. Depression-anxiety relationships with chronic physical conditions: results from the world mental health surveys. J Affect Disord. 2007;103:113-20.

27. Wells KB, Golding JM, Burnam MA. Affective, substance use, and anxiety disorders in persons with arthritis, diabetes, heart disease, high blood pressure, or chronic lung conditions. Gen Hosp Psychiatry. 1989;11:320-7.

28. Katon W, Ciechanowski P. Impact of major depression on chronic medical illness. J Psychosom Res. 2002;53:859-63.

29. Buist-Bouwman MA, De Graaf R, Vollebergh WAM, Ormel J. Comorbidity of physical and mental disorders and the effect on work-loss days. Acta Psychiatr Scand. 2005;111:436-43.

30. Kupfer DJ, Frank E, Perel JM, Cornes C, Mallinger AG, Thase ME, et al. Fiveyear outcome for maintenance therapies in recurrent depression. Arch Gen Psychiatry. 1992;49:767-73.

31. Ballenger JC. Remission rates in patients with anxiety disorders treated with paroxetine. J Clin Psychiatry. 2004;65:1696-707.

32. Yonkers KA, Dyck IR, Warshaw M, Keller MB. Factors predicting the clinical course of generalised anxiety disorder. Br J Psychiatry. 2000;176:544-9.

33. Patrick DL, Kinne S, Engelberg RA, Pearlman RA. Functional status and perceived quality of life in adults with and without chronic conditions. J Clin Epidemiol. 2000;53:779-85.

34. Saricoban HE, Ozen A, Harmanci K, Razi C, Zahmacioglu O, Cengizlier MR. Common behavioral problems among children with asthma: is there a role of asthma treatment? Ann Allergy Asthma Immunol. 2011;106:200-4.

35. Goodwin RD, Jacobi F, Thefeld W. Mental disorders and asthma in the community. Arch Gen Psychiatry. 2003;60:1125-30.

36. Pietrzak RH, Morasco BJ, Blanco C, Grant BF, Petry NM. Gambling level and psychiatric and medical disorders in older adults: results from the national epidemiologic survey on alcohol and related conditions. Am J Geriatr Psychiatry. 2007;15:301-13.

37. McGrath DS, Barrett SP. The comorbidity of tobacco smoking and gambling: a review of the literature. Drug Alcohol Rev. 2009;28:676-81.

38. Griffiths M, Wardle H, Orford J, Sproston K, Erens B. Gambling, alcohol, consumption, cigarette smoking and health: findings from the 2007 British gambling prevalence survey. Addict Res Theory. 2010;18:208-23.

39. Petry NM, Stinson FS, Grant BF. Comorbidity of DSM-IV pathological gambling and other psychiatric disorders: results from the national epidemiologic survey on alcohol and related conditions. J Clin Psychiatry. 2005;66:564-74.

40. Quigley H, MacCabe JH. The relationship between nicotine and psychosis. Ther Adv Psychopharmacol. 2019;9:2045125319859969.

41. Stroup TS, Gray N. Management of common adverse effects of antipsychotic medications. World Psychiatry. 2018;17:341-56.

42. Stevens L, Rodin I. Antipsychotic drugs. In: Psychiatry: an illustrated colour text. London: Elsevier Health Sciences; 2011. p. 24-5.

43. van der Feltz-Cornelis CM, Biemans H, Timmer J. Hearing voices: Does it give your patient a headache? A case of auditory hallucinations as acoustic aura in migraine. Neuropsychiatr Dis Treat. 2012:8:105.

44. Bourgeois J, Mistry H. Migraine-associated psychosis and subsequent renal transplant. Psychosomatics. 2010;51:77-9.

45. Fuller GN, Marshall A, Flint J, Lewis S, Wise RJS. Migraine madness: recurrent psychosis after migraine. J Neurol Neurosurg Psychiatry. 1993;56:416-8.

46. Swets M, Dekker J, van Emmerik-van Oortmerssen K, Smid GE, Smit F, de Haan $L$, et al. The obsessive compulsive spectrum in schizophrenia, a metaanalysis and meta-regression exploring prevalence rates. Schizophr Res. 2014:152:458-68

47. Zink M, Schirmbeck F, Rausch F, Eifler S, Elkin H, Solojenkina X, et al. Obsessive-compulsive symptoms in at-risk mental states for psychosis: associations with clinical impairment and cognitive function. Acta Psychiatr Scand. 2014;130:214-26.
48. Chong SA, Abdin E, Sherbourne C, Vaingankar J, Heng D, Yap M, et al Treatment gap in common mental disorders: the Singapore perspective. Epidemiol Psychiatr Sci. 2012;21:195.

49. American Psychiatric Association. Diagnostic and Statistical Manual of Mental Disorders. 4th ed. Washington, DC: American Psychiatric Association; 2000.

50. Borsboom D, Fried El, Epskamp S, Waldorp LJ, van Borkulo CD, van der Maas HL, et al. False alarm? A comprehensive reanalysis of "evidence that psychopathology symptom networks have limited replicability" by Forbes, Wright, Markon, and Krueger (2017). J Abnorm Psychol. 2017;50(3):353-66.

\section{Publisher's Note}

Springer Nature remains neutral with regard to jurisdictional claims in published maps and institutional affiliations.
Ready to submit your research? Choose BMC and benefit from:

- fast, convenient online submission

- thorough peer review by experienced researchers in your field

- rapid publication on acceptance

- support for research data, including large and complex data types

- gold Open Access which fosters wider collaboration and increased citations

- maximum visibility for your research: over $100 \mathrm{M}$ website views per year

At BMC, research is always in progress.

Learn more biomedcentral.com/submissions 